\title{
Charge State-Dependent Fragmentation of Oligonucleotide/Metal Complexes
}

\author{
Karin M. Keller and Jennifer S. Brodbelt \\ Department of Chemistry and Biochemistry, The University of Texas at Austin, Austin, Texas, USA
}

Collision-activated dissociation (CAD) has been employed to assess the gas-phase fragmentation behavior of a series of 1:1 oligodeoxynucleotide (ODN):metal complexes over a range of charge states, using several ten-residue ODNs and a wide array of alkali, alkaline earth, and transition metals. For parent species in low to intermediate charge states, complexation with $\mathrm{Ca}^{+2}, \mathrm{Sr}^{+2}$, or Ba ${ }^{+2}$ altered the relative intensity of M-B species, promoting loss of cytosine over loss of guanine. The relative intensities of sequence ions were largely unaffected. This behavior was most prevalent for isomeric sequences with complementary residues at the $5^{\prime}$ - and 3 '-termini, suggesting that metal complexation may change the gas-phase conformation and/or conformational dynamics for some sequences. In higher charge states, some ODN/ $\mathrm{Ba}^{+2}$ complexes produced abundant fragment ions corresponding to metallated $\mathrm{a}_{\mathrm{n}}{ }^{-\mathrm{m}}$ species, which are not commonly observed in CAD mass spectra for deprotonated ODNs. The formation of these ions was most favored for complexes between $\mathrm{Ba}^{+2}$ and ODN sequences with a thymine residue at Position 6. Literature precedent exists for the formation of $a_{n}{ }^{-m}$ ions from sequences in which covalent modification generates one or more neutral sites along the phosphate backbone. ODN/metal adducts in high charge states possess only a few acidic protons, and the juxtaposition of these neutral phosphate groups near thymine residues and the bound $\mathrm{Ba}^{+2}$ ion may direct formation of the metallated $\mathrm{a}_{\mathrm{n}}{ }^{-\mathrm{m}}$ species. (J Am Soc Mass Spectrom 2005, 16, 28-37) (c) 2004 American Society for Mass Spectrometry

$\mathrm{M}$ etal ions are critical to the in vivo structure and function of DNA and RNA. Mono- and divalent cations are thought to induce bending in DNA duplexes [1, 2], and are also known to stabilize triplex [3, 4], and quadruplex [5, 6] structures. Metal cations are also required for the proper folding and function of many forms of RNA, including most ribozymes $[7,8]$. The interactions of DNA with several natural products [9] and synthetic drugs and drug candidates $[10,11]$ are known to be metal-mediated.

Mass spectrometry (MS) is well-established as a useful tool for the structural characterization and sequencing of nucleic acids [12-14], and has also been employed to characterize a number of nucleic acid/metal ion interactions [15]. Several previous studies have focused on the interactions of the anticancer therapeutic cisplatin or its derivatives with DNA [16-22]. Relatively few studies have addressed binary interactions of nucleic acids and metal cations [23-27]. Most of these studies have focused primarily on complexes with the smaller alkali and alkaline earth metals (e.g., $\mathrm{Na}^{+}, \mathrm{Mg}^{+2}$ ), although a few complexes with transition metals $[25,26]$ or f-block elements $[23,25]$ have also been investigated. The fragmentation behavior of these complexes has been characterized using

Published online December 13, 2004

Address reprint requests to Dr. J. S. Brodbelt, Department of Chemistry and Biochemistry, The University of Texas, 1 University Station A5300, Austin, TX 78712, USA. E-mail: jbrodbelt@mail.utexas.edu parent species in relatively low charge states (often -2), but intermediate and high charge state precursors have not been studied. A more complete characterization of the entire charge state envelope produced by electrospray ionization would not only enhance our theoretical understanding of the complexation properties of oligonucleotide anions, but might also reveal characteristic fragmentation behavior that could facilitate sequencing experiments. For example, one can envision the analysis of oligonucleotide/metal complexes as an alternative or complementary strategy to the analysis of conventional deprotonated oligonucleotides, as is commonly done for other types of biological molecules [28-30]. This concept is particularly relevant when considering that metal complexation adds positive charge centers amidst the sites of deprotonation of the net negatively charged oligonucleotides, thus altering the mechanisms of dissociation.

The present study, therefore, explores the effect of metal complexation on the fragmentation patterns of oligodeoxynucleotides (ODNs) in several different charge states. A number of different alkali, alkaline earth, and transition metals and several ten-residue sequences were employed to form 1:1 complexes, which were subjected to collision-activated dissociation (CAD) in a quadrupole ion trap mass spectrometer. For low charge state precursors, distinct changes were observed in the relative intensities of some product ions for free vs. metallated ODNs. For high charge state precursors, the metal complexes of some sequences exhibited un- 

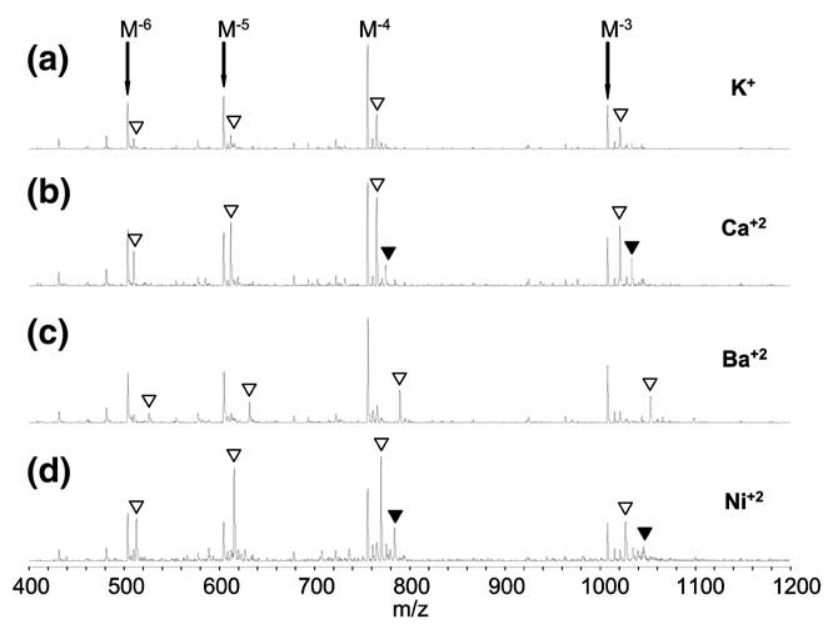

Figure 1. ESI mass spectra for GCGAATTCGC in the presence of various metal salts. (a) $\mathrm{KCl}$; (b) $\mathrm{CaCl}_{2}$; (c) $\mathrm{BaCl}_{2}$; and (d) $\mathrm{NiBr}_{2}$. Complexes at the 1:1 stoichiometry are marked with open triangles, and complexes at the 1:2 stoichiometry are marked with filled triangles.

usual but highly diagnostic fragmentation pathways not commonly observed for free ODNs. The sequence and metal dependence of these results were evaluated to more fully expose the factors controlling these fragmentation processes.

\section{Experimental}

HPLC-purified oligodeoxynucleotides (ODNs) were obtained from TriLink Biotechnologies (San Diego, CA), Invitrogen (Carlsbad, CA), or IDT (Coralville, IA). When necessary, ODNs were converted to the ammonium salt form by either centrifugal filtration or ethanol precipitation from ammonium acetate. Alkali, alkaline earth, and transition metal salts (bromides or chlorides) were obtained from Aldrich (St. Louis, MO) and were used as received. Samples containing equimolar amounts of oligonucleotide and metal salt at $20-40 \mu \mathrm{M}$ in 1:3 methanol:water were infused at $3 \mu \mathrm{L} /$ minute into the electrospray source of a ThermoQuest LCQ Duo quadrupole ion trap mass spectrometer operating in negative ion mode. In CAD experiments, activation voltages were applied at a level required to reduce the precursor ion to $\sim 10 \%$ of its original intensity.

\section{Results and Discussion}

Oligonucleotides are known to bind metal cations with high affinity. When equimolar amounts of metal salts were added to the ammonium form of a model oligonucleotide, the decamer GCGAATTCGC, ODN/metal complexes were readily observed for a wide variety of mono- and divalent metal cations, including $\mathrm{K}^{+}, \mathrm{Rb}^{+}$, $\mathrm{Cs}^{+}, \mathrm{Ca}^{+2}, \mathrm{Sr}^{+2}, \mathrm{Ba}^{+2}, \mathrm{Mn}^{+2}, \mathrm{Co}^{+2}, \mathrm{Ni}^{+2}, \mathrm{Ag}^{+}, \mathrm{Cd}^{+2}$, $\mathrm{Hg}^{+2}$, and $\mathrm{Pb}^{+2}$. Several representative ESI spectra are shown in Figure 1. For all metals investigated, the 1:1 ODN:metal stoichiometry was observed in multiple charge states (typically -2 to -6 ), although higher stoichiometries were also observed for the late transition metals $\left(\mathrm{Ni}^{+2}\right.$, as shown in Figure $1 \mathrm{~d}$; also $\mathrm{Co}^{+2}$ and $\left.\mathrm{Ag}^{+}\right)$. The exact mode by which metal cations bind DNA remains unclear, but some evidence indicates that transition metals can bind DNA nucleobases, while alkali and alkaline earth metals generally prefer the backbone phosphodiester groups [31]. The relative intensities for 1:1 ODN:metal complexes in Figure 1 could be interpreted as support for this notion: transition metals may produce higher stoichiometries and greater signal intensities because they can readily bind the bases and therefore need not compete with the ammonium counterions for phosphodiester binding sites. Alkali and alkaline earth cations, on the other hand, may compete less effectively for phosphodiester sites occupied by ammonium counterions, which are present in excess relative to the added metal salts.

To evaluate the effect of different metals on oligonucleotide fragmentation, $\mathrm{CAD}$ spectra were first acquired for the $[O D N-n H]^{-n}$ ions $(n=-2$ to -6$)$ formed with GCGAATTCGC. CAD experiments were then performed for the analogous [ODN $\left.-\mathrm{nH}+\mathrm{M}^{+\mathrm{m}}\right]^{-(\mathrm{n}-\mathrm{m})}$ ions ( $\mathrm{n}-\mathrm{m}=-2$ to -6$)$ formed by $1: 1$ complexes of GCGAATTCGC with a series of metal cations. Compared to the deprotonated precursors, some of the metal adducts demonstrated distinctly different fragmentation behavior in both low and high charge states. The metals to most likely produce unusual fragmentation were identified, and a representative metal $\left(\mathrm{Ba}^{+2}\right)$ was chosen for additional experiments with different oligonucleotides to investigate the sequence dependence of these dissociation processes.

\section{Fragmentation of Low Charge State Precursors}

Dissociation data for the -2 charge state of GCGAATTCGC are shown in Figure 2. For the deprotonated ODN, the most abundant ions in the spectrum represent
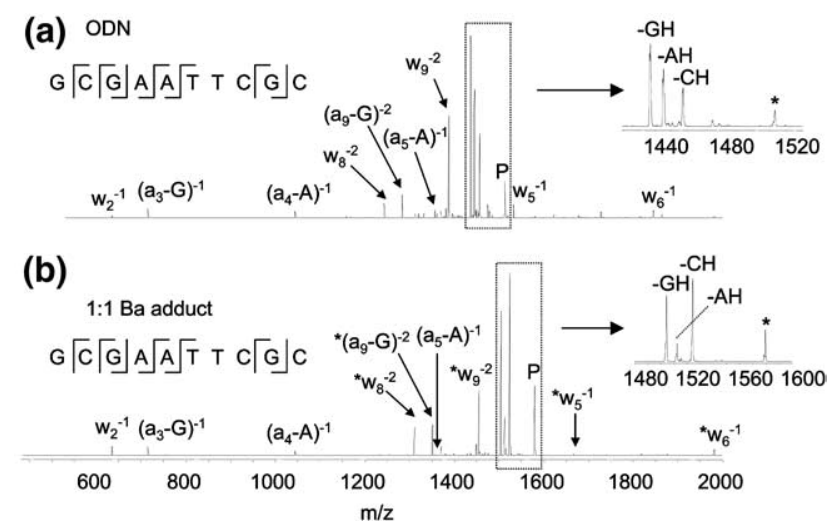

Figure 2. CAD spectra for the -2 charge state of GCGAATTCGC and its $1: 1$ complex with $\mathrm{Ba}^{+2}$. (a) ODN alone $(0.75 \mathrm{~V} / 30 \mathrm{~ms})$ and (b) $\mathrm{Ba}^{+2}$ adduct $(0.88 \mathrm{~V} / 30 \mathrm{~ms})$. Parent ions are marked $\mathrm{P}$, and fragments identified with an asterisk and a standard sequence ion identifier (e.g., ${ }^{*} \mathrm{w}_{8}{ }^{-2}$ ) correspond to sequence ions that retain the metal ion. 


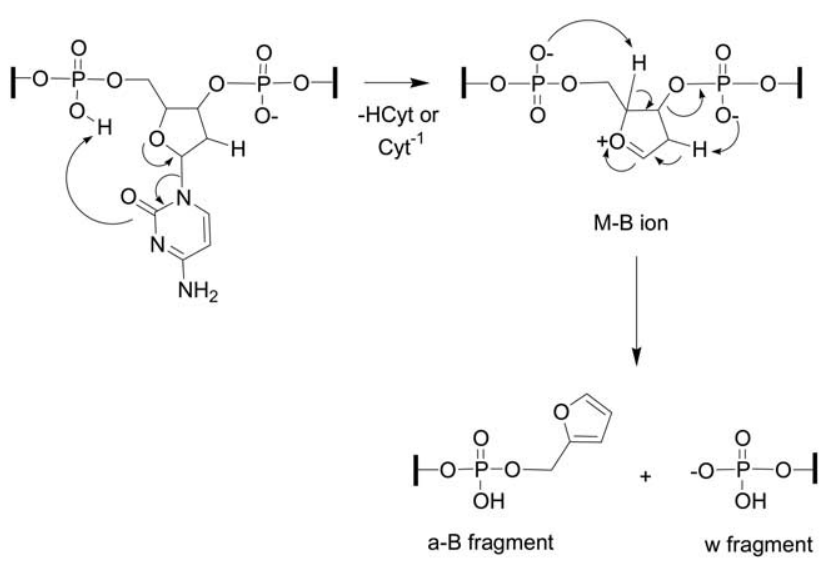

Scheme 1. General mechanism for oligonucleotide base loss and backbone cleavage [30, 31].

loss of neutral nucleobases (detailed in Figure 2a, inset), resulting in $\mathrm{M}-\mathrm{B}$ ions that retain the intact phosphate backbone. Secondary dissociation of these ions produced an array of backbone cleavage products ("sequence ions") labeled $\mathrm{w}_{\mathrm{n}}$ and $\mathrm{a}_{\mathrm{n}}-\mathrm{B}$ according to the McLuckey nomenclature [32]. The general mechanism shown in Scheme $\mathbf{1}$ has been proposed to explain the formation of these kinds of fragments [33, 34]. The assortment of sequence ions visible in Figure $2 \mathrm{a}$ indicates that cleavage has occurred at nearly every interresidue junction along the phosphate backbone, as indicated by the series of slash marks overlaid on the sequence shown in Figure 2a. As originally described by Favre et al. [35], the charges on these sequence ions convey the preferred locations of the negative charges. For example, the $\mathrm{w}$ ion series in Figure 2a consisted of $\mathrm{w}_{2}{ }^{-1}, \mathrm{w}_{5}{ }^{-1}, \mathrm{w}_{6}{ }^{-1}, \mathrm{w}_{8}{ }^{-2}$, and $\mathrm{w}_{9}{ }^{-2}$ species. The fact that $\mathrm{w}_{5}{ }^{-2}$ and $\mathrm{w}_{6}{ }^{-2}$ species were not observed suggests that in the activated parent species, the total charge was not distributed statistically along the phosphate backbone, but was instead confined near the $5^{\prime}$ - and $3^{\prime}$-termini. Analysis of the a-B ion series in Figure 2a supports the same conclusion, which is also consistent with results for different sequences in previous studies [35].

Dissociation data were then acquired for the -2 charge state of 1:1 complexes of this ODN with a series of metal cations, and a representative CAD spectrum, acquired for the 1:1 barium complex, is shown in Figure $2 \mathrm{~b}$. The $\mathrm{m} / \mathrm{z}$ values for many of the resulting fragments indicated that the ODN-Ba ${ }^{+2}$ interaction survived collisional activation. These fragments include the M-B species (Figure 2b inset) as well as a number of metallated $\mathrm{w}$ and $\mathrm{a}-\mathrm{B}$ ions, which are marked with asterisks to distinguish them from non-metallated $\mathrm{w}$ and a-B species. The combined array of both metallated and non-metallated sequence ions indicates that the $\mathrm{Ba}^{+2}$ complex produced the same overall sequence coverage as the free ODN (Figure 2a), which is consistent with previous dissociation studies conducted with ODN/ metal complexes [23, 24]. In addition, the distribution of charge among the sequence ions suggests that one negative charge was localized near each end of the sequence, as described above for the free ODN. It is important to note, however, that metal cations provide partial charge balance for species of the general formula $\left[\mathrm{ODN}-\mathrm{nH}+\mathrm{M}^{+\mathrm{m}}\right]^{-(\mathrm{n}-\mathrm{m})}$, and that the fragment ion charges can only be used to determine the position of the "excess" charges. Additional deprotonation sites counterbalanced by the metal cation must also exist, and these cannot be determined solely from the charge states of the sequence ions. The preferred localization of the metal cation itself can be estimated, however, by examining which sequence ions retain the metal [23]. In Figure $2 b$, for example, the smallest $\mathrm{w}$ species retaining $\mathrm{Ba}^{+2}$ was the ${ }^{*} \mathrm{~W}_{5}{ }^{-1}$ ion and the smallest a-B species retaining $\mathrm{Ba}^{+2}$ was the ${ }^{*}\left(\mathrm{a}_{8}-\mathrm{C}\right)^{-2}$ ion. The approximate location of the $\mathrm{Ba}^{+2}$ ion should correspond to the portion of the original sequence common to both these fragments (i.e., the pTpTp motif), as illustrated in Scheme 2. The fact that the metal resides near the middle of the sequence is consistent with results reported for series of sodium-adducted ODNs [24].

In several respects (sequence coverage, the location of the negative charges, and the location of the metal cation), the data in Figure 2 correlate well with previous observations as noted above. The fragmentation behavior of the $\mathrm{Ba}^{+2}$ adduct was unusual in one respect, as illustrated by the insets in Figure 2a and b, which are expansions of the base loss region of the CAD spectra. For the deprotonated ODN, the most intense M-B ion stemmed from loss of neutral guanine, which is typical of mixed-base oligonucleotide sequences in low charge states [36]. For the $\mathrm{Ba}^{+2}$ adduct, however, loss of cytosine was the predominant process as indicated by the enhanced intensity of the $\mathrm{M}-\mathrm{CH}$ ion. As shown in Scheme 1, M-B species are intermediates that dissociate

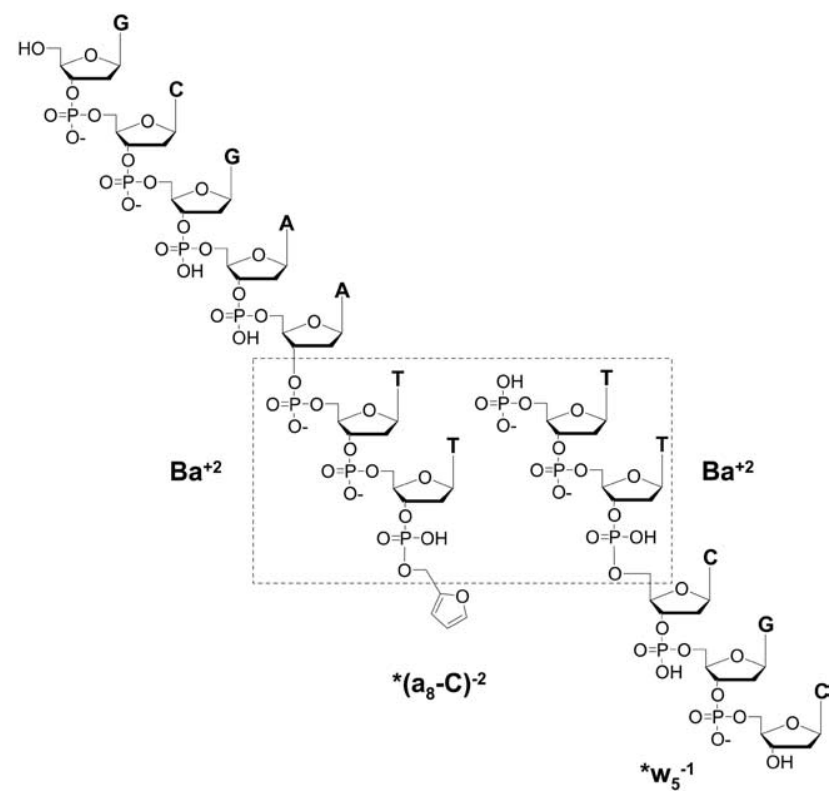

Scheme 2. Identification of the approximate binding site for $\mathrm{Ba}^{+2}$ on GCGAATTCGC. 


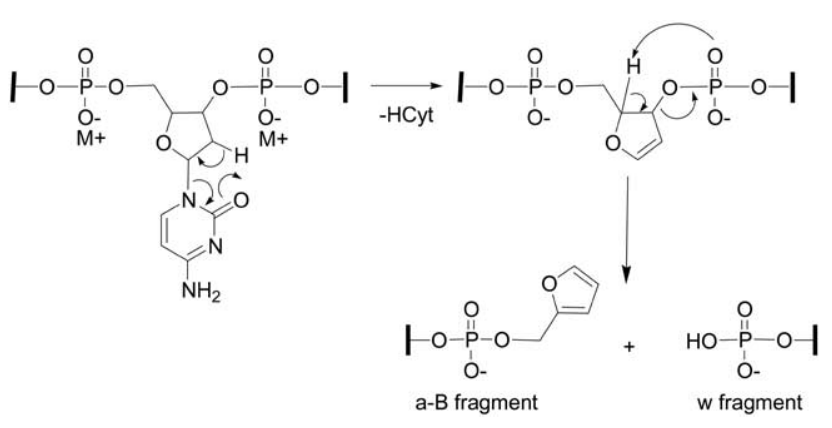

Scheme 3. Proposed mechanism for base loss from ODNs bearing metal counterions [27].

further to yield sequence ions. While loss of cytosine in and of itself is not atypical, loss of either adenine or guanine usually predominates, although the reasons for this are not well understood [37]. The enhanced loss of cytosine seen in Figure 2a was found to depend on the identity of the metal complexed to the ODN, as illustrated in Figure 3, which shows the base loss regions of the CAD mass spectra for ODN complexes containing different metal ions. Collisional activation of alkali or transition metal complexes produced different base loss patterns than the free ODN (Figure 3a), as indicated by representative spectra for the $\mathrm{K}^{+}$and $\mathrm{Ni}^{+2}$ complexes (Figure $3 \mathrm{c}$ and e). However, loss of cytosine was most strongly favored for the complexes with the alkaline earth metals, although the underlying reasons for this behavior are unclear. The relative intensity of the $\mathrm{M}-\mathrm{CH}$

(a)
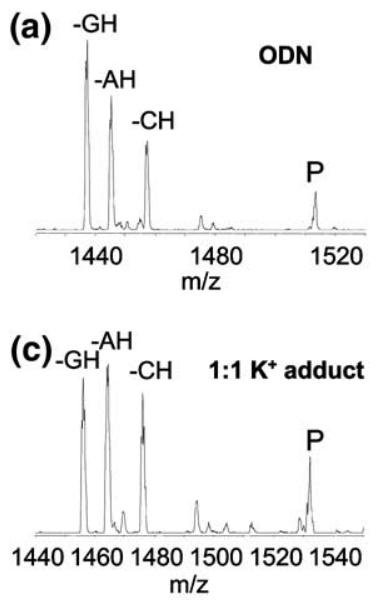

(e)

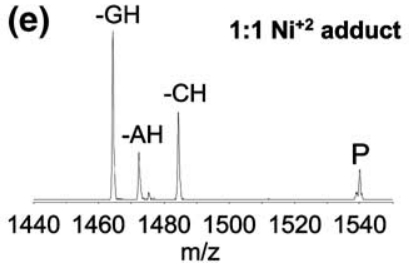

Figure 3. Base loss region of CAD spectra for GCGAATTCGC and several 1:1 metal complexes in the -2 charge state. (a) ODN alone $(0.75 \mathrm{~V} / 30 \mathrm{~ms})$; (b) $1: 1$ adduct with $\mathrm{Ba}^{+2}(0.85 \mathrm{~V} / 30 \mathrm{~ms}) ;$ (c) $1: 1$ adduct with $\mathrm{K}^{+}(0.95 \mathrm{~V} / 30 \mathrm{~ms})$; (d) $1: 1$ adduct with $\mathrm{Ca}^{+2}$ $(0.9 \mathrm{~V} / 30 \mathrm{~ms})$; and (e) $1: 1$ adduct with $\mathrm{Ni}^{+2}(0.78 \mathrm{~V} / 30 \mathrm{~ms})$. Parent ions are marked $\mathrm{P}$.

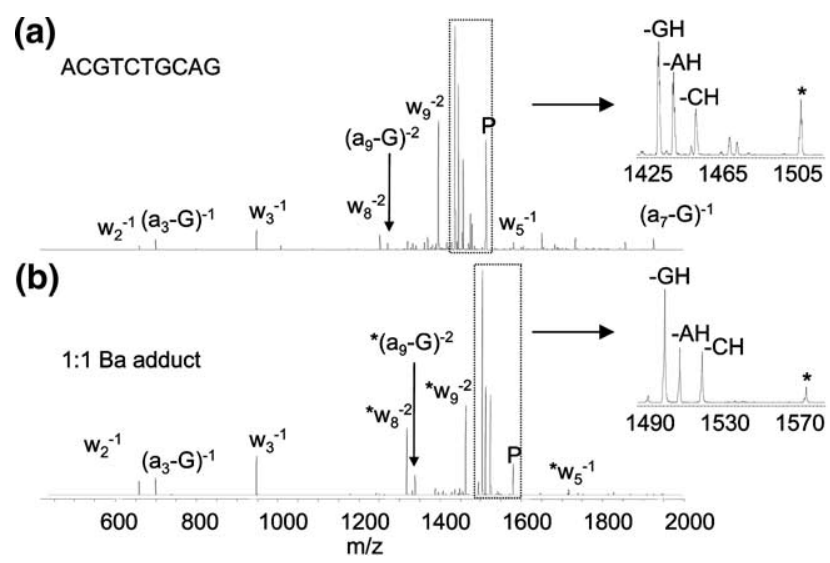

Figure 4. CAD spectra for the -2 charge state of ACGTCTGCAG and its 1:1 complex with $\mathrm{Ba}^{+2}$. (a) ODN alone $(0.75 \mathrm{~V} / 30 \mathrm{~ms})$ and (b) $\mathrm{Ba}^{+2}$ adduct $(0.78 \mathrm{~V} / 30 \mathrm{~ms})$. Parent ions are marked $\mathrm{P}$, and fragments identified with an asterisk and a standard sequence ion identifier (e.g., ${ }^{*} \mathrm{w}_{8}{ }^{-2}$ ) correspond to sequence ions that retain the metal ion.

ions were greatest for 1:1 adducts with $\mathrm{Ba}^{+2}, \mathrm{Sr}^{+2}$ and $\mathrm{Ca}^{+2}$; CAD spectra for $\mathrm{Ba}^{+2}$ and $\mathrm{Ca}^{+2}$ are shown in Figure $3 b$ and $d$, respectively.

Previous studies have shown that loss of cytosine is enhanced for fully metallated oligonucleotides, i.e., those where all phosphodiester counterions are metals [27]. To explain this enhancement the mechanism illustrated in Scheme 3 was proposed and supported with CAD results for deuterated precursor ions [27]. In this route, protons are transferred to the nucleobase from the $2^{\prime}$ position of the deoxyribose ring, rather than the $5^{\prime}$-phosphate group as in the standard mechanism (Scheme 1). Subsequent base loss and cleavage at the $3^{\prime}$ phosphate then generates the usual $\mathrm{w}$ and a-B sequence ions. Under these conditions, loss of cytosine and thymine typically predominates over loss of adenine and guanine because the pyrimidines possess tautomeric forms that place electron-rich moieties in the proximity of the ribose ring. The mechanism depicted in Scheme 3 does not fully explain the dissociation patterns observed in Figure $3 b-e$, however. This route predicts facile loss of thymine as well as cytosine, and essentially no loss of thymine was observed for any of the metal complexes investigated in our study. Furthermore, this mechanism was proposed to be operative at much higher metal:ODN stoichiometries, i.e., when all backbone phosphate protons are replaced with metal counterions. The parent ions in Figure $3 \mathrm{~b}$ and $\mathrm{d}$ contain only one metal cation, and therefore retain several acidic protons available for transfer to a nucleobase.

In an attempt to gain more insight into these unusual base losses, additional experiments were undertaken to determine what, if any, sequence dependence might exist. Fragmentation patterns were acquired for the -2 charge state of several other 1:1 decamer:metal complexes. To facilitate comparisons with the data in Figure 2, these additional sequences all shared the base composition $\mathrm{A}_{2} \mathrm{C}_{3} \mathrm{G}_{3} \mathrm{~T}_{2}$, and because the alkaline earth 
metals enhanced loss of cytosine most strongly, $\mathrm{Ba}^{+2}$ was chosen as the metal ion in these experiments. CAD results obtained for the ODNs GAATTCGCGC, GCGCGAATTC, CGCTTAAGCG, and AAGCGCGCTT were quite similar to those shown in Figure 2: loss of guanine dominated for the $[\mathrm{M}-2 \mathrm{H}]^{-2}$ precursors, and loss of cytosine dominated for the $\left[\mathrm{M}-4 \mathrm{H}+\mathrm{Ba}^{+2}\right]^{-2}$ precursors (data not shown). This uniform behavior suggests that the position of the cytosine residues along the sequence played little role in the observed fragmentation behavior. However, as shown in Figure $4, \mathrm{Ba}^{+2}$ adduction did not significantly affect the base loss pattern for the sequence ACGTCTGCAG, relative to that observed for the deprotonated ODN. In this case, the loss of guanine dominated the CAD spectra of both the free ODN (Figure 4a) and the 1:1 barium adduct (Figure $4 \mathrm{~b}$ ), and the loss of cytosine was comparable for both parent ions. It is not entirely clear why the CAD patterns for the ACGTCTGCAG ions differ from the patterns observed for the other decamers. However, for all five sequences for which the loss of cytosine was enhanced upon barium complexation, the residue at the 3 '-terminus was the Watson-Crick complement of the residue at the $5^{\prime}$-terminus. This is not true of ACGTCTGCAG, the only sequence that did not exhibit a change in its base loss pattern. This points to intramolecular base pairing, and therefore gas-phase conformation, as a significant factor: metal complexation may change the gas-phase conformation (and/or conformational dynamics) for some sequences, providing access to alternative mechanisms for proton transfer and subsequent base loss. Relatively little is known about the gas-phase conformation of oligonucleotides, although some results from ion mobility experiments have recently appeared [38-42].

\section{Fragmentation of Intermediate Charge State Precursors}

Fragmentation patterns for 1:1 metal complexes with GCGAATTCGC in the -3 and -4 charge states were also determined to assess any metal-dependent differences in dissociation behavior. For alkali and transition metals, CAD spectra for these charge states produced nearly complete sequence coverage (only sites $3^{\prime}$ to thymine resisted cleavage), but few systematic differences were noted in comparing the type, number, and abundance of product ions obtained from the metal complexes with those produced by the oligonucleotide alone. Spectra for complexes with the alkaline earth metals were somewhat distinct in that the base loss patterns were again strongly affected by the presence of the metal ion. The CAD spectrum for the $1: 1 \mathrm{Ba}^{+2}$ complex in the -3 charge state (not shown) produced $(\mathrm{M}-\mathrm{BH})^{-3}$ species with intensity patterns similar to those visible in Figure 2, which indicates that the factors controlling base loss processes for ODNs versus their barium complexes were also operative at a higher (a)
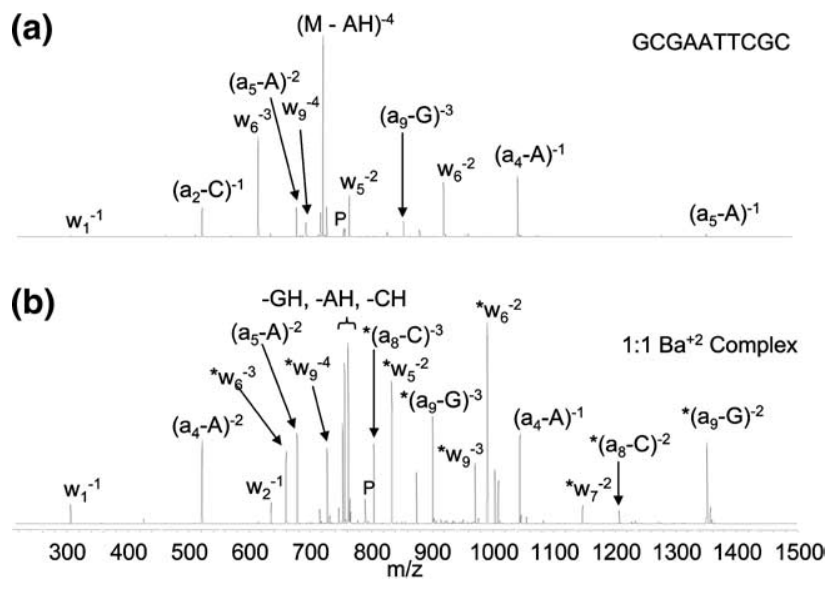

Figure 5. CAD spectra for the -4 charge state of GCGAATTCGC and its $1: 1$ complex with $\mathrm{Ba}^{+2}$. (a) ODN alone $(0.75 \mathrm{~V} / 30 \mathrm{~ms})$ and (b) $\mathrm{Ba}^{+2}$ adduct $(0.80 \mathrm{~V} / 30 \mathrm{~ms})$. Parent ions are marked $\mathrm{P}$, and fragments identified with an asterisk and a standard sequence ion identifier (e.g., ${ }^{*} \mathrm{w}_{8}{ }^{-2}$ ) correspond to sequence ions that retain the metal ion.

charge state. CAD spectra acquired for the -4 charge states of GCGAATTCGC and its $1: 1 \mathrm{Ba}^{+2}$ complex are given in Figure $5 a$ and $b$, respectively, and the base loss patterns in Figure $5 \mathrm{a}$ and $\mathrm{b}$ are again different. For this charge state, however, the parent ions lose adenine as the major process, which is entirely consistent with previous literature reports for collisional activation of deprotonated oligonucleotides in intermediate charge states [36, 43, 44]. As was observed for the -2 charge state, the $\mathrm{Ba}^{+2}$ complex in the -4 charge state produced the same overall sequence coverage as the deprotonated ODN alone, and analysis of the metallated sequence ions indicated that the metal cation again localized preferentially at the pTpTp motif of the parent ion. Comparison of Figures $2 \mathrm{~b}$ and $5 \mathrm{~b}$ illustrates that the $\mathrm{M}-\mathrm{B}$ species became less dominant for the metal complex as charge state increased. This may mean that the difference between the threshold energy levels required for base loss and (secondary) backbone cleavage is smaller for metal complexes in higher versus lower charge states. A similar difference in threshold energies may also explain the fact that sequence ions produced by the ODN:Ba ${ }^{+2}$ complex in Figure $5 \mathrm{~b}$ are more intense than the sequence ions visible in Figure 5a. In addition, the intensity of sequence ions at higher $m / z$ values than the parent ion was often greater in the spectrum of the $\mathrm{Ba}^{+2}$ complex than in the spectrum for the deprotonated ODN alone (ex. $\mathrm{w}_{6}{ }^{-2}$ versus ${ }^{*} \mathrm{w}_{6}{ }^{-2}$ in Figures 5a and $b)$.

\section{Fragmentation of High Charge State Precursors}

Dissociation data were then acquired for the 1:1 metal complexes of GCGAATTCGC in higher charge states $(-5$ and -6$)$. The results indicate that, as for the low and intermediate charge states, complexes with the alkaline earth metals produced the most distinct behav- 


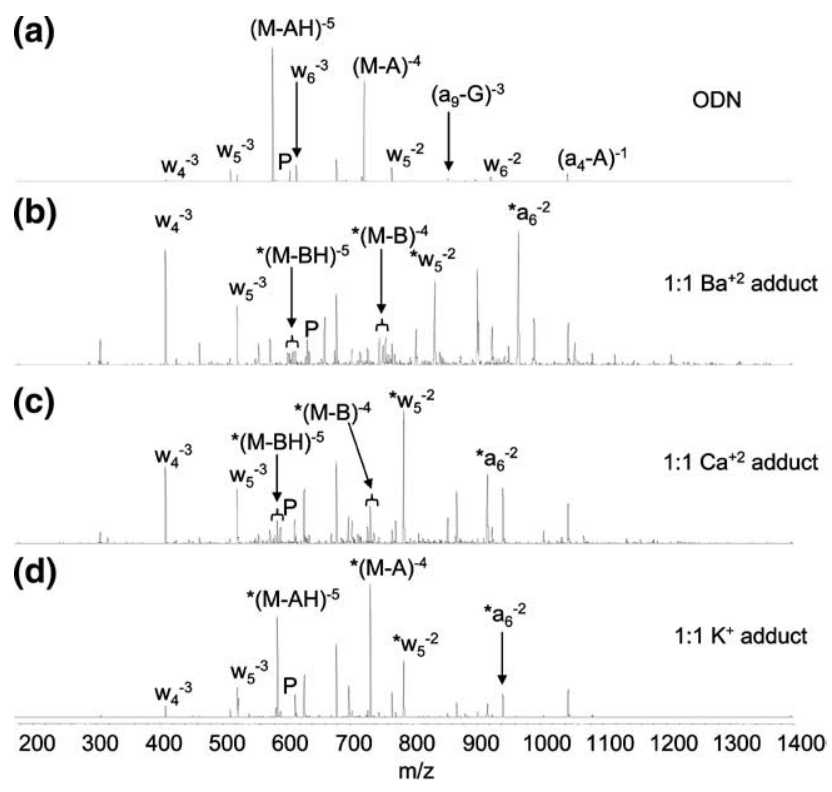

Figure 6. CAD spectra for the -5 charge state of GCGAATTCGC and its 1:1 complexes with several metal cations. (For clarity, only a restricted number of fragment ions are labeled.) (a) ODN alone $(0.75 \mathrm{~V} / 30 \mathrm{~ms}) ; \mathrm{Ba}^{+2}$ complex $(0.88 \mathrm{~V} / 30 \mathrm{~ms}) ;(\mathrm{c}) \mathrm{Ca}^{+2}$ complex $(0.88 \mathrm{~V} / 30 \mathrm{~ms})$; and $(\mathrm{d}) \mathrm{K}^{+}$complex $(0.90 \mathrm{~V} / 30 \mathrm{~ms})$. Parent ions are marked $\mathrm{P}$, and fragments identified with an asterisk and a standard sequence ion identifier (e.g., ${ }^{*} \mathrm{~W}_{8}{ }^{-2}$ ) correspond to sequence ions that retain the metal ion.

ior. Dissociation data for the -5 charge state of GCGAATTCGC and its 1:1 $\mathrm{Ba}^{+2}$ adduct are given in Figure $6 \mathrm{a}$ and $\mathrm{b}$. The spectrum in Figure $6 \mathrm{~b}$ is remarkable in several respects: the M-B ions, which normally dominate CAD spectra for oligonucleotides acquired in quadrupole ion trap instruments, occur with unusually low signal intensities. Furthermore, the dominant product ions, at $\mathrm{m} / \mathrm{z} 965.5$ and 408.7 , are consistent with the assignments ${ }^{*} \mathrm{a}_{6}{ }^{-2}$ and $\mathrm{w}_{4}{ }^{-3}$, respectively. The CAD spectra of oligonucleotides rarely contain $a_{n}{ }^{-m}$ ions as major species. The presence of the ${ }^{*} \mathrm{a}_{6}{ }^{-2}$ ion along with the complementary $\mathrm{w}_{4}{ }^{-3}$ ion with similar signal intensity indicates that direct, site-specific backbone cleavage

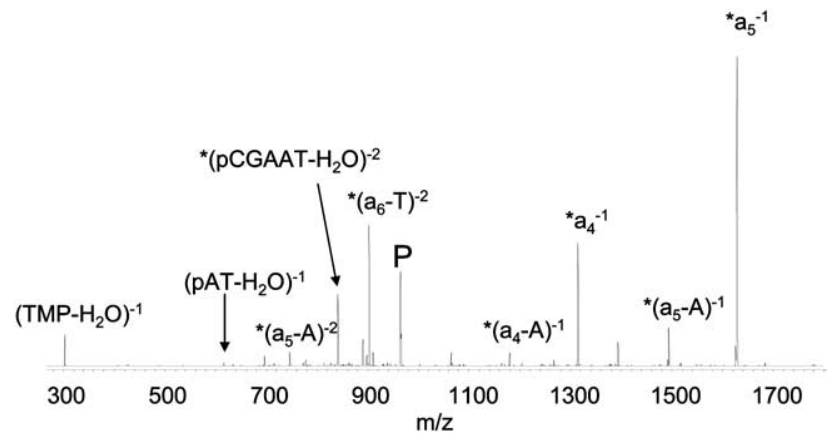

Figure 7. $\mathrm{MS}^{3}$, $\left(\mathrm{GCGAATTCGC}+\mathrm{Ba}^{+2}-7 \mathrm{H}\right)^{-5} \rightarrow \mathrm{m} / \mathrm{z} 965.5 \rightarrow$ ? $(0.88 \mathrm{mv} / 30 \mathrm{~ms} ; 0.95 \mathrm{~V} / 30 \mathrm{~ms})$. The parent ion is marked $\mathrm{P}$ and fragments identified with an asterisk and a standard sequence ion identifier (e.g., ${ }^{*} \mathrm{w}_{8}{ }^{-2}$ ) correspond to sequence ions that retain the metal ion. (no preceding base loss) has taken place. To confirm the assignment of $\mathrm{m} / \mathrm{z}$ 965.5, an $\mathrm{MS}^{3}$ experiment was performed, and the resulting spectrum (Figure 7) supports assignment of $m / z 965.5$ as the ${ }^{*} \mathrm{a}_{6}{ }^{-2}$ ion. Fragments assigned as ${ }^{*} \mathrm{a}_{5}{ }^{-1}$ and ${ }^{*} \mathrm{a}_{4}{ }^{-1}$ ions were observed along with the complementary [thymine monophosphate $\left.\mathrm{H}_{2} \mathrm{O}\right]^{-1}$ and $\left[\mathrm{pAT}-\mathrm{H}_{2} \mathrm{O}\right]^{-1}$ ions, indicating that the ${ }^{*} \mathrm{a}_{6}{ }^{-2}$ ion also dissociated by direct backbone cleavage. Some products of cleavage preceded by base loss (likely by the mechanism shown in Scheme 2) are also visible (e.g., ${ }^{*}\left[\mathrm{a}_{6}-\mathrm{T}\right]^{-2}$ ) in Figure 7.

The formation of the unusual ${ }^{*} \mathrm{a}_{6}{ }^{-2}$ species was found to be strongly metal dependent. The relative intensity of the ${ }^{*} \mathrm{a}_{6}{ }^{-2} / \mathrm{w}_{4}{ }^{-3}$ complementary pair decreased in the order $\mathrm{Ba}^{+2}, \mathrm{Sr}^{+2}>\mathrm{Ca}^{+2}, \mathrm{~Pb}^{+2}>\mathrm{K}^{+}, \mathrm{Rb}^{+}$, $\mathrm{Cs}^{+}, \mathrm{Mn}^{+2}, \mathrm{Co}^{+2}, \mathrm{Ni}^{+2}, \mathrm{Cd}^{+2}, \mathrm{Hg}^{+2}$. Representative spectra acquired for complexes with $\mathrm{Ca}^{+2}$ and $\mathrm{K}^{+}$are shown in Figure $6 \mathrm{c}$ and d, respectively. Comparing the CAD spectra for the complexes with $\mathrm{Ba}^{+2}$ (ionic radius $149 \mathrm{pm})$ and $\mathrm{Ca}^{+2}(114 \mathrm{pm})$ indicates that larger metal ions promote the formation of the ${ }^{*} \mathrm{a}_{6}{ }^{-2}$ product ion more effectively than smaller ions carrying the same ionic charge (Figure 6B versus $\mathrm{C}$ ). Likewise, comparing data for $\mathrm{Ba}^{+2}$ and $\mathrm{K}^{+}$, which have similar ionic radii (149 versus $152 \mathrm{pm}$ ) but different net charges, indicates that greater ionic charge also facilitates formation of the ${ }^{*} \mathrm{a}_{6}{ }^{-2}$ product ion (Figure $6 \mathrm{~b}$ versus $\mathrm{d}$ ). Results for other metal ions suggests that other factors are probably also operative: for example, the complex with $\mathrm{Pb}^{+2}$ gave the $* \mathrm{a}_{6}{ }^{-2}$ ion in somewhat lower intensity than the complex with $\mathrm{Sr}^{+2}$, which could be due to a difference in electronegativity $\left(0.95\right.$ for $\mathrm{Pb}^{+2}$ versus 1.87 for $\left.\mathrm{Sr}^{+2}\right)$, orbital configuration (two versus zero valence electrons), or both.

The formation of the ${ }^{*} \mathrm{a}_{6}{ }^{-2}$ species was also found to be strongly sequence dependent. Data for the relative intensity of the ${ }^{*} \mathrm{a}_{6}{ }^{-2}$ fragment for different ten-residue sequences is compiled in Table 1 and presented in a semi-quantitative fashion. The barium complexes of two unrelated sequences (ATGCTACGAG and GACTACAAGT) did not produce ${ }^{*} \mathrm{a}_{6}{ }^{-2}$ ions, showing that the direct backbone cleavage process is not a general phenomenon. The first five entries in Table 1, taken as a

Table 1. Sequence dependence of *a ion formation upon CAD of $1: 1 \mathrm{Ba}^{2+}$ adducts ( -5 charge states)

\begin{tabular}{lc}
\hline Sequence & Relative Intensity, *a lons \\
\hline \hline GCGAATTCGC & +++ \\
GCGATATCGC & - \\
GCAAATTTGC & +++ \\
GCATATATCG & ++ \\
GCGCATGCGC & ++ \\
GCGAGTTCGC & ++ \\
GCGAACTCGC & + \\
GCGCGAATTC & + \\
GAATTCGCGC & + \\
CGCTTAAGCG & + \\
ATGCTACGAG & - \\
GACTACAAGT & - \\
\hline
\end{tabular}


collective, indicate that the middle of the sequence greatly influences the direct backbone cleavage process. In a particularly striking result, replacing the central "AATT" motif in the original sequence with the alternating sequence "ATAT" completely prevented the formation of ${ }^{*} \mathrm{a}_{6}{ }^{-2}$ ion. The sequence GCAAATTTGC, which incorporates additional $\mathrm{A}$ and $\mathrm{T}$ residues, produced a strong ${ }^{*} \mathrm{a}_{6}{ }^{-2}$ ion, but the alternating version of this sequence (GCATATATGC) also gave the ${ }^{*} \mathrm{a}_{6}{ }^{-2}$ product with significant (albeit somewhat lower) intensity. The decamer GCGCATGCGC, which contains fewer $\mathrm{A} / \mathrm{T}$ residues, also produced the ${ }^{*} \mathrm{a}_{6}{ }^{-2}$ ion with substantial signal intensity. Taken together these results indicate that the AT motif at Positions 5 and 6 is critical, and that sequential $\mathrm{A}$ and $\mathrm{T}$ residues around these positions is supportive. Point substitutions at these sites, as in the sequences GCGAGTTCGC and GCGAACTCGC, show that the thymine residue at Position 6 is more critical to the formation of the ${ }^{*} \mathrm{a}_{6}{ }^{-2}$ ion than the adenine at Position 5. Three sequence variants (GCGCGAATTC, GAATTCGCGC, and CGCTTAAGCG) all produced metallated a ions in only low abundance, which indicates that both the position and directionality of the AT motif are significant. This may mean that the proximity of the AT motif to the metal center may be critical, because for all of the decamers listed in Table 1, the distribution of the metal cation among the observed fragment ions indicates that the $\mathrm{Ba}^{+2}$ ions are bound near the middle of the sequence (i.e., near Positions 5 and 6).

Direct cleavage of the phosphate backbone of deprotonated oligonucleotides to yield $a_{n}{ }^{-m}$ ions has been observed in certain circumstances. Favre et al. observed a number of $a_{n}{ }^{-m}$ ions upon collisional activation of deprotonated polythymine, a result that was ascribed to the low proton affinity of thymine [35]. The formation of $\mathrm{a}_{\mathrm{n}}{ }^{-\mathrm{m}}$ ions has also been observed as highly diagnostic for the modification sites of photomodified ODNs in which two nucleobases are covalently bonded. Because two nucleobases are linked, the conventional base loss can not occur at the photomodified sites [45-47]. ODNs with strictly uncharged backbone sites (either meth-

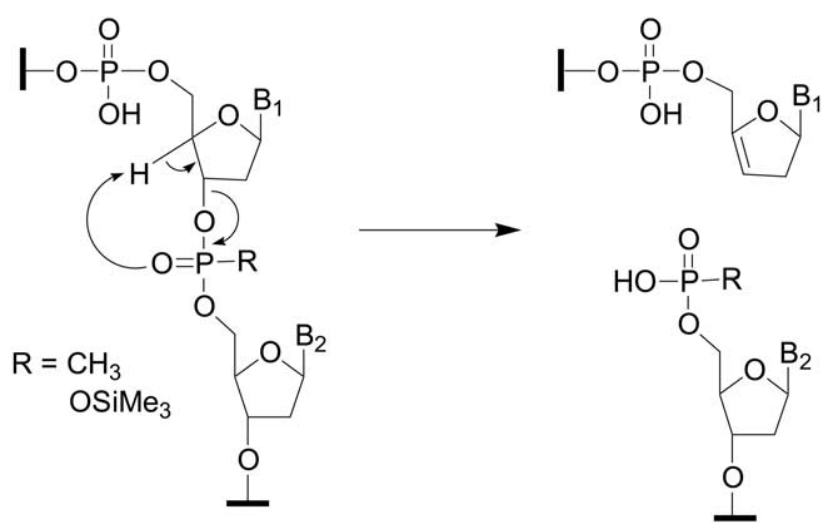

Scheme 4. Proposed mechanism for direct cleavage of the phosphate backbone to yield $a_{n}{ }^{-m}$ ions [42\}.
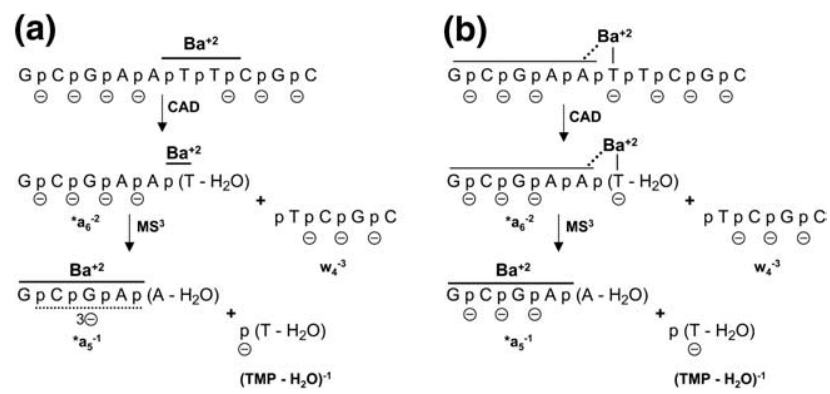

Scheme 5. Possible route to *a ions from the -5 charge state of $\left(\text { GCGAATTCGC }+\mathrm{Ba}^{+2}-7 \mathrm{H}\right)^{-5}$. (a) Negative charges assigned exclusively to phosphodiester groups and (b) negative charges allowed on both phosphodiester groups and nucleobase moieties.

ylphosphonates [48] or TMS-derivatized phosphates [49]) have also been shown to undergo direct backbone cleavage at a site adjacent to the neutral linkage. One mechanism proposed to explain such cases [48], shown in Scheme 4, involves proton transfer from the $4^{\prime}$ position of ribose to the neutral phosphodiester linkage followed by cleavage of the $3^{\prime}$ ribose-linker bond. Presumably, this mechanism in Scheme 4 could also operate in cases where a standard but neutral phosphodiester linkage is present, i.e., when the $\mathrm{R}$ group in Scheme 4 is $\mathrm{OH}$. Neutral backbone sites must be present in the ODN $/ \mathrm{Ba}^{+2}$ complexes under investigation: the decamers contain a total of nine acidic (i.e., phosphodiester) hydrogens, so $\left[\mathrm{ODN}-\mathrm{nH}+\mathrm{Ba}^{+2}\right]^{(\mathrm{n}-2)}$ complexes carrying a net charge of -5 would retain two acidic protons on the phosphate backbone. These considerations lead to the hypothesis that for certain oligonucleotide/metal complexes, metal coordination may sequester acidic protons at certain positions along the phosphate backbone.

This concept is illustrated in Scheme 5a for the [d(GCGAATTCGC) $\left.-7 \mathrm{H}+\mathrm{Ba}^{+2}\right]^{-5}$ ion. In accordance with CAD data for this complex (Figure $6 \mathrm{~b}$ ), the $\mathrm{Ba}^{+2}$ cation is shown to be bound somewhere along the internal pTpTp subsequence. The negative charges are assumed to reside only on phosphodiester groups and are assigned to phosphodiesters 1-4 and 7-9 (relative to the 5 '-terminus) in order to leave neutral sites at phosphodiesters 5 and 6 . By the hypothesis given above, a neutral site at Position 6 could lead to direct backbone cleavage by the mechanism in Scheme 4 to produce the $* \mathrm{a}_{6}{ }^{-2}$ ion along with its complement, the $\mathrm{w}_{4}{ }^{-3}$ ion. The presence of a neutral phosphodiester at Position 5 in the ${ }^{*} \mathrm{a}_{6}{ }^{-2}$ ion could then yield an ${ }^{*} \mathrm{a}_{5}{ }^{-1}$ product upon $\mathrm{MS}^{3}$, which was indeed observed (Figure 7). Experimentally, however, the metallated ${ }^{*} a_{5}{ }^{-1}$ species seen in Figure 7 carries a net charge of -1 , and the complementary (TMP $-\mathrm{H}_{2} \mathrm{O}$ ) ion (which contains the critical neutral phosphodiester) also carried a net charge of -1 . This is difficult to reconcile by the route shown in Scheme 5a, where phosphodiester 5 is assigned as a neutral site, unless extensive proton transfer from other sites takes place. In addition, the distribution of charge in Scheme 5a tends to maximize Coulombic repulsion. 
The premise underlying Scheme 5a (that negative charges reside exclusively at phosphodiester groups) was therefore reconsidered. The base moieties of certain nucleotides (uridine, deoxythymidine, and guanosine) do exhibit some acidic character and can be deprotonated in alkaline solution $(\mathrm{pKa}=9.5,10.0$, and 9.6, respectively) [50]. Furthermore, certain metal complexes are known to bind N3-deprotonated thymine and uridine at physiological $\mathrm{pH}$ [51-53]. In the gas phase, internal Coulombic repulsion in highly charged oligonucleotide anions could encourage deprotonation of guanine and/or thymine residues. These considerations are incorporated into an alternative route, presented in Scheme $5 \mathrm{~b}$, which permits deprotonation at both phosphodiester and nucleobase moieties. If it is assumed that the critical thymine residue at Position 6 is deprotonated and a specific interaction between this residue and the metal cation is maintained (allowing the possibility of additional interactions along the GCGAA motif), then a neutral site can be assigned to phosphodiester 5, as shown. (A third neutral backbone site, required for charge balance, could theoretically reside at several locations but is shown at Position 4.) Like the scenario in Scheme $\mathbf{5 a}$, this permits direct cleavage of the parent species to produce an ${ }^{*} \mathrm{a}_{6}{ }^{-2}$ product ion according to the route in Scheme 4. However, Scheme $\mathbf{5 b}$ better reconciles the $\mathrm{MS}^{3}$ data obtained for the resulting ${ }^{*} \mathrm{a}_{6}{ }^{-2}$ ion in several respects. First, charge balance in the conversion of ${ }^{*} \mathrm{a}_{6}{ }^{-2}$ to ${ }^{*} \mathrm{a}_{5}{ }^{-1}+$ $\left(\mathrm{TMP}-\mathrm{H}_{2} \mathrm{O}\right)^{-1}$ by Scheme 4 is more readily explained if phosphodiester 4 is neutral. Second, the presence of a formally charged thymine residue allows the possibility of anionic base loss, which could explain the large difference in relative intensities of the ${ }^{*} \mathrm{a}_{5}{ }^{-1}$ and (TMP $\left.\mathrm{H}_{2} \mathrm{O}\right)^{-1}$ ions in Figure 7. (As complementary species, these ions would be expected to form with similar relative intensities. A $(\mathrm{T}-\mathrm{H})^{-1}$ ion, if formed, would be seen at $m / z 125$, which is below the low mass cutoff of the spectrum in Figure 7). Third, the presence of the $* \mathrm{a}_{4}{ }^{-1}$ product ion in Figure 7 could form by the route in Scheme 4 if phosphodiester 4 is neutral. A reasonable route to this product ion is less readily conceived from Scheme 5a.

In sum, Scheme $5 \mathrm{~b}$ presents a picture for the formation of metallated $a_{n}{ }^{-m}$ fragments from [d(GCGAATTCGC) $\left.-7 \mathrm{H}+\mathrm{Ba}^{+2}\right]^{-5}$ ion that is generally consistent

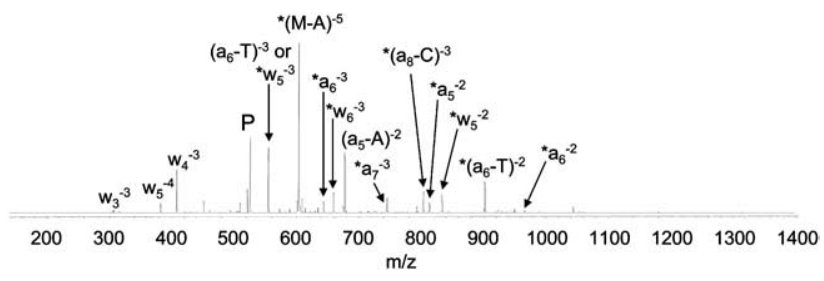

Figure 8. CAD spectrum for the 1:1 adduct of GCGAATTCGC and $\mathrm{Ba}^{2+}$ in the -6 charge state $(0.90 \mathrm{~V} / 30 \mathrm{~ms})$. The parent ion is marked $\mathrm{P}$, and fragments identified with an asterisk and a standard sequence ion identifier (e.g., ${ }^{*} \mathrm{w}_{8}{ }^{-2}$ ) correspond to sequence ions that retain the metal ion. with what is known about the factors influencing the direct cleavage process. The low proton count agrees with the observed charge state dependence. The notion that a (deprotonated) thymine residue at Position 6 might be involved is generally consistent with the sequence dependence indicated in Table 1. It should be acknowledged, however, that Scheme $\mathbf{5}$ rationalizes only the major fragmentation pathways observed for the $\left[\mathrm{d} \text { (GCGAATTCGC) }-7 \mathrm{H}+\mathrm{Ba}^{+2}\right]^{-5}$ ion (and its ${ }^{*} \mathrm{a}_{6}{ }^{-1}$ product ion). Other, less significant pathways are also observed in both Figure 6b and Figure 7, implying that multiple populations with different deprotonation and/or metal complexation sites may well exist and interchange.

The possibility of multiple populations is also highlighted by CAD data obtained for 1:1 metal complexes in the -6 charge state. The $\mathrm{Ba}^{+2}$ complexes of only a few of the decamers listed in Table 1 (GCGAATTCGC, GCAAATTTGC and GCGAGTTCGC) produced detectable ${ }^{*} a_{n}-m$ ions from the -6 charge state precursor. A representative spectrum for the barium complex of GCGAATTCGC is shown in Figure 8, and illustrates that for this charge state the metallated $a_{n}{ }^{-m}$ species formed in lower relative intensity but greater variety. If negative charges occur exclusively at phosphodiester moieties, then ions of the formula [ODN $\left.-\mathrm{nH}+\mathrm{Ba}^{+2}\right]^{-6}$ would retain only one neutral backbone site. If this neutral site drives direct backbone cleavage, as Scheme 4 hypothesizes, the distribution of different ${ }^{*} \mathrm{a}_{\mathrm{n}}{ }^{-\mathrm{m}}$ ions in Figure 8 indicates that this "last" neutral site delocalizes over several positions along the backbone.

\section{Conclusions}

Overall results for the fragmentation behavior of 1:1 ODN:metal complexes show that the alkaline earth metals affected the dissociation preferences of the reference 10-residue ODN more strongly than alkali or transition metals. For low to intermediate charge states, metal adduction altered the relative intensity of $M-B$ species produced for several ten-residue ODNs, promoting loss of cytosine rather than loss of guanine. The relative intensities of sequence ions were largely unaffected. This behavior was most prevalent for $\mathrm{Ca}^{+2}, \mathrm{Sr}^{+2}$, and $\mathrm{Ba}^{+2}$ over that of alkali or transition metal ions, suggesting a dependence on charge density and less stringent coordination geometry of the metal center, and for isomeric ODNs with complementary residues at the 5 ' - and 3 '-termini. This suggests that metal complexation may change the gas-phase conformation for some sequences, possibly providing access to alternative mechanisms for proton transfer to and subsequent loss of the nucleobase moieties.

In higher charge states, CAD of some metal adducts of GCGAATTCGC produced intense fragment ions corresponding to metallated $\mathrm{a}_{6}{ }^{-2}$ ions. These species result from direct cleavage of the phosphate backbone (with no prior loss of nucleobase) and are not commonly observed for deprotonated ODNs. The forma- 
tion of these ions from metal adducted ODNs is highly dependent on the identity of the metal, being most favored for large divalent cations with empty valence shells such as $\mathrm{Ba}^{+2}$ and $\mathrm{Sr}^{+2}$. This behavior was also strongly dependent on sequence, being most prevalent for sequences with a thymine residue at Position 6 . Literature precedent exists for the formation of $a_{n}{ }^{-n}$ ions from sequences in which covalent modification generates one or more neutral sites along the phosphate backbone. ODN/metal adducts in high charge states possess only a few acidic protons, and the juxtaposition of these neutral phosphate groups near thymine residues and the bound $\mathrm{Ba}^{+2}$ ion may direct formation of the metallated $\mathrm{a}_{6}{ }^{-2}$ species.

The CAD patterns of the metal complexes provide comparable and often complementary sequence information to that obtained from conventional deprotonated ODNs and should be particularly relevant for structural characterization of metal-mediated DNAdrug complexes.

\section{Acknowledgments}

The authors thank Professor Michael Bowers for important input in the interpretation of fragmentation data for complexes in high charge states. Support from the Robert A. Welch Foundation (F-1155) and NIH (RO1 GM65956) is gratefully acknowledged.

\section{References}

1. Hud, N. V.; Polak, M. DNA-cation interactions: The major and minor grooves are flexible ionophores. Curr. Opin. Struct. Biol. 2001, 11, 293-301.

2. McFail-Isom, L.; Sines, C. C.; Williams, L. D. DNA structure: Cations in charge? Curr. Opin. Struct. Biol. 1999, 9, 298-304.

3. Frank-Kamenetskii, M. D.; Mirkin, S. M. Triplex DNA structures. Annu. Rev. Biochem. 1995, 64, 65-95.

4. Gilbert, D. E.; Feigon, J. Multistranded DNA structures. Curr. Opin. Struct. Biol. 1999, 9, 305-314.

5. Chowdhury, S.; Bansal, M. Effect of coordinated ions on structure and flexiblity of parallel G-quandruplexes: A molecular dynamics study. J. Biomol. Struct. Dyn. 2000, 18, 11-28.

6. Hardin, C. C.; Perry, A. G.; White, K. Thermodynamic and kinetic characterization of the dissociation and assembly of quadruplex nucleic acids. Biopolymers 2000, 56, 147-194.

7. Draper, D. E.; Shiman, R. Stabilization of RNA tertiary structure by monovalent cations. J. Mol. Biol. 2000, 302, 79-91.

8. Draper, D. E. A guide to ions and RNA structure. RNA 2004, 10, 335-343.

9. Chakrabarti, S.; Bhattacharyya, D.; Dasgupta, D. Structural basis of DNA recognition by anticancer antibiotics, chromomycin A3, and mithramycin: Roles of minor groove width and ligand flexibility. Biopolymers 2000, 56, 85-95.

10. Fan, J. Y.; Sun, D.; Yu, H.; Kerwin, S. M.; Hurley, L. H. Self-assembly of a quinobenzoxazine- $\mathrm{Mg} 2+$ complex on DNA: A new paradigm for the structure of a drug-DNA complex and implications for the structure of the quinolone bacterial gyrase-DNA complex. J. Med. Chem. 1995, 38, 408424.

11. Zeng, Q.; Kwok, Y.; Kerwin, S. M.; Mangold, G.; Hurley, L. H. Design of new topoisomerase II inhibitors based upon a quinobenzoxazine self-assembly model. J. Med. Chem. 1998, 41, $4273-4278$.
12. Ni, J.; Pomerantz, S. C.; Rozenski, J.; Zhang, Y.; McCloskey, J. A. Interpretation of oligonucleotide mass spectra for determination of sequence using electrospray ionization and tandem mass spectrometry. Anal. Chem. 1996, 68, 1989-1999.

13. Nordhoff, E.; Kirpekar, F.; Roepstorff, P. Mass spectrometry of nucleic acids. Mass Spectrom. Rev. 1996, 15, 69-138.

14. Limbach, P. A. Indirect mass spectrometric methods for characterizing and sequencing oligonucleotides. Mass Spectrom. Rev. 1997, 15, 297-336.

15. Beck, J. L.; Colgrave, M. L.; Ralph, S. F.; Sheil, M. M. Electrospray ionization mass spectrometry of oligonucleotide complexes with drugs, metals, and proteins. Mass Spectrom. Rev. 2001, 20, 61-87.

16. Gonnet, F.; Kocher, F.; Blais, J.; Bolbach, G.; Chottard, J.; Tabet, J. C. Analysis of reaction between d(TTGGCCAA) and a Pt-complex by enzymatic degradation, ESI and MALDI. Inorg. Chem. 1996, 35, 1653-1658.

17. Lowe, G.; McCloskey, J. A.; Ni, J.; Vilaivan, T. A mass spectrometric investigation of the reaction between 4,4'vinylenedipyridine bis $\left[2,2^{\prime}: 6^{\prime}, 2^{\prime \prime}\right.$-terpyridine platinum(II)] and

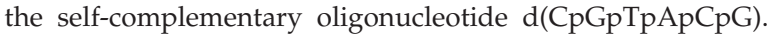
Bioinorg. Med. Chem. 1996, 4, 1007-1013.

18. Troujman, H.; Chottard, J. C. Comparison between HPLC and capillary electrophoresis for the separation and identification of the platination products of oligonucleotides with cis$[\mathrm{Pt}(\mathrm{NH} 3) 2(\mathrm{H} 2 \mathrm{O}) 2] 2+$ and $[\mathrm{Pt}(\mathrm{NH} 3) 3(\mathrm{H} 2 \mathrm{O})] 2+$. Anal. Biochem. 1997, 252, 177-185.

19. Xu, N.; Pasa-Tolic, L.; Smith, R. D.; Ni, S.; Thrall, B. D. Electrospray ionization-mass spectrometry study of the interaction of cisplatin-adducted oligonucleotides with human XPA minimal binding domain protein. Anal. Biochem. 1999, 272, 26-33.

20. Iannitti-Tito, P.; Weimann, A.; Wickham, G.; Sheil, M. M. Structural analysis of drug-DNA adducts by tandem mass spectrometry. Analyst 2000, 125, 627-634.

21. Kloster, M. B. G.; Hannis, J. C.; Muddiman, D. C.; Farrell, N. Consequences of nucleic acid conformation on the binding of a trinuclear platinum drug. Biochemistry 1999, 38, 14731-14737.

22. Carte, N.; Legendre, F.; Leize, E.; Potier, N.; Reeder, F.; Chottard, J. C.; Dorsselaer, A. Determination by electrospray mass spectrometry of the outer sphere association constants of DNA/platinum complexes using 20-mer oligonucleotides and $([\mathrm{Pt}(\mathrm{NH} 3) 4] 2+, 2 \mathrm{Cl}-)$ or $([\mathrm{Pt}(\mathrm{py}) 4] 2+, 2 \mathrm{Cl}-)$. Anal. Biochem. 2000, 284, 77-86.

23. Wu, Q.; Cheng, X.; Hofstadler, S. A.; Smith, R. D. Specific metal-oligonucleotide binding studied by high resolution tandem mass spectrometry. J. Mass Spectrom. 1996, 31, 669-675.

24. Favre, A.; Gonnet, F.; Tabet, J. -C. Location of the Na+ cation in negative ions of DNA evidenced by using MS2 experiments in ion trap mass spectrometry. Int. J. Mass Spectrom. 1999, 190, 303-312.

25. Hettich, R. L. Formation and characterization of iron-oligonucleotide complexes with matrix-assisted laser desorption/ ionization Fourier transform ion cyclotron resonance mass spectrometry. J. Am. Soc. Mass Spectrom. 1999, 10, 941-949.

26. Hettich, R. L. Investigating the effect of transition metal ion oxidation state on oligodeoxyribonucleotide binding by matrix-assisted laser desorption/ionization Fourier transform ion cyclotron resonance mass spectrometry. Int. J. Mass Spectrom. 2001, 204, 55-75.

27. Wang, Y.; Taylor, J. S.; Gross, M. L. Fragmentation of electrospray-produced oligodeoxynucleotide ions adducted to metal ions. J. Am. Soc. Mass Spectrom. 2001, 12, 550-556.

28. Gatlin, C. L.; Turecek, F. Electrospray ionization of inorganic and organometallic complexes. In Electrospray Ionization Mass Spectrometry: Fundamentals, Instrumentation, and Applications; Cole, R. B., Ed; Wiley: New York, 1997, pp 527-570. 
29. Colton, R., D'Agostino, A.; Traeger, J. C. Electrospray mass spectrometry applied to inorganic and organometallic chemistry. Mass Spectrom. Rev. 1995, 14, 79-106.

30. Bayer, E.; Gfrorer, P.; Rentel, C. Coordination-ionspray-MS (CIS-MS), a universal detection and characterization method for direct coupling with separation techniques, Angew. Chem. Int. Ed. 1999, 38, 992-995.

31. Bloomfield, V. A.; Crothers, D. M.; Tinoco, I. J. Physical chemistry of nucleic acids; Harper and Row: New York, 1974, pp $420-429$.

32. McLuckey, S. A.; Van Berkel, G. J.; Glish, G. L. Tandem mass spectrometry of small, multiply charged oligonucleotides. J. Am. Soc. Mass Spectrom. 1992, 3, 60-70.

33. Wang, Z.; Wan, K. X.; Ramanathan, R.; Taylor, J. S.; Gross, M. L. Structure and fragmentation mechanisms of isomeric T-rich oligodeoxynucleotides: A comparison of four tandem mass spectrometric methods. J. Am. Soc. Mass Spectrom. 1998, 9, 683-691.

34. Wan, K. X.; Gross, J.; Hillenkamp, F.; Gross, M. L. Fragmentation mechanisms of oligodeoxynucleotides studied by H/D exchange and electrospray ionization tandem mass spectrometry. J. Am. Soc. Mass Spectrom. 2001, 12, 193-205.

35. Favre, A.; Gonnet, F.; Tabet, J.-C. Location of the negative charge(s) on the backbone of single-stranded deoxyribonucleic acid in the gas phase. Eur. J. Mass Spectrom. 2000, 6389, 389-396.

36. Luo, H.; Lipton, M. S.; Smith, R. D. Charge effects for differentiation of oligodeoxynucleotide isomers containing 8-oxo-dG residues. J. Am. Soc. Mass Spectrom. 2002, 13, 195-199.

37. Daneshfar, R.; Klassen, J. S. Arrhenius activation parameters for the loss of neutral nucleobases from deprotonated oligonucleotide anions in the gas phase. J. Am. Soc. Mass Spectrom. 2004, 15, 55-64.

38. Hoaglund, C. S.; Liu, Y.; Ellington, A. D.; Pagel, M.; Clemmer, D. E. Gas-phase DNA: Conformations of oligothymidine ions. J. Am. Chem. Soc. 1997, 119, 9051-9052.

39. Gidden, J.; Bushnell, J. E.; Bowers, M. T. Gas-phase conformations and folding energetics of oligonucleotides: dTG- and dGT-. J. Am. Chem. Soc. 2001, 123, 5610-5611.

40. Gidden, J.; Bowers, M. T. Gas-phase conformational and energetic properties of deprotonated dinucleotides. Eur. Phys. J. D 2002, 20, 409-419.

41. Gidden, J.; Bowers, M. T. Gas-phase conformations of deprotonated and protonated mononucleotides determined by ion mobility and theoretical modeling. J. Phys. Chem. B 2003, 107, 12829-12837.

42. Gidden, J.; Bowers, M. T. Gas-phase conformations of deprotonated trinucleotides (dGTT-, dTGT-, and dTTG-): The ques- tion of zwitterion formation. J. Am. Soc. Mass Spectrom. 2003, 14, 161-170.

43. Little, D. P.; Speir, J. P.; Senko, M. W.; O'Connor, P. B.; McLafferty, F. W. Infrared multiphoton dissociation of large multiply charged ions for biomolecule sequencing. Anal. Chem. 1994, 66, 2809-2815.

44. Keller, K. M.; Brodbelt, J. S. Collisionally activated dissociation and infrared multiphoton dissociation of oligonucleotides in a quadrupole ion trap. Anal. Biochem. 2004, 326, 200-210.

45. Wang, Y.; Taylor, J. -S.; Gross, M. L. Differentiation of isomeric photomodified oligodeoxynucleotides by fragmentation of ions producted by matrix-assisted laser desorption ionization and electrospray ionization. J. Am. Soc. Mass Spectrom. 1999, 10, 329-338.

46. Wang, Y.; Taylor, J. -S.; Gross, M. L. Isolation and mass spectrometric characterization of dimeric adenine photoproducts in oligodeoxynucleotides, Chem. Res. Toxicol. 2001, 14, 738-745.

47. Zeng, Y.; Wang, Y. Facile formation of an intrastrand crosslink lesion between cytosine and guanine upon pyrex-filtered UV light irradiation of $\mathrm{d}\left({ }^{\mathrm{Br}} \mathrm{CG}\right)$ and duplex DNA containing 5-bromocytosine. J. Am. Chem. Soc. 2004, 126, 6552-6553.

48. Bartlett, M. G.; McCloskey, J. A.; Manalili, S.; Griffey, R. H. The effect of backbone charge on the collision-induced dissociation of oligonucleotides. J. Mass Spectrom. 1996, 31, 1277-1283.

49. O'Hair, R. A. J.; McLuckey, S. A. Trimethylsilyl derivatization of nucleic acid anions in the gas phase. Int. J. Mass Spectrom. Ion Processes 1997, 162, 183-202.

50. Shabarova, Z. A.; Bogdanov, A. A. Advanced organic chemistry of nucleic acids; VCH: Weinheim, 1994, pp 93-96.

51. Shionoya, M.; Kimura, E.; Shiro, M. A new ternary zinc(II) complex with [12]aneN4 (=1,4,7,10-tetraazacyclododecane) and AZT (= 3'-azido-3'-deoxythymidine). Highly selective recognition of thymidine and its related nucleosides by a zinc(II) macrocyclic tetraamine complex with novel complementary associations. J. Am. Chem. Soc. 1993, 115, 67306737.

52. Shionoya, M.; Ikeda, T.; Kimura, E.; Shiro, M. Novel "multipoint" molecular recognition of nucleobases by a new zinc(II) complex of acridine-pendant cyclen (cyclen $=1,4,7,10-$ tetraazacyclododecane). J. Am. Chem. Soc. 1994, 116, $3848-$ 3859.

53. Kikuta, E.; Murata, M.; Katsube, N.; Koike, T.; Kimura, E. Novel recognition of thymine base in double-stranded DNA by zinc(II)-macrocyclic tetraamine complexes appended with aromatic groups. J. Am. Chem. Soc. 1999, 121, 5426-5436. 